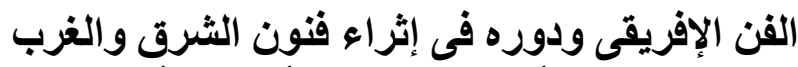

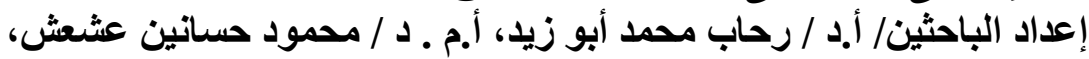

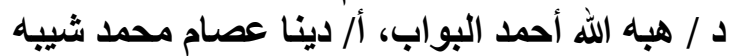

\title{
الفن الإفريقى ودوره فى إثراء فنون الشرق والغرب
}

\section{African art and its role in enriching the arts of East and West}

$$
\text { اعداد }
$$

\section{دينا عصام محمد شيبه}

الدارسة بمرحلة الماجستير بقسم التربية الفنبة - كلية التربية النوعية - جامعة

$$
\text { بورسعيد }
$$

$$
\text { أ.د/ رحاب محمد أبو زيد }
$$

أستاذ الاشغال الفنية قسم التربية الفنية - كلية التربية النوعية - جامعة بورسعيد

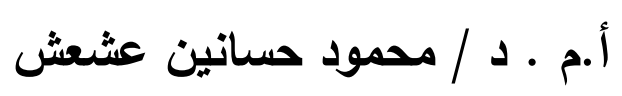

أستاذ الاشغال الفنية المساعد المتفرغ قسم التربية الفنية - كلية التربية النوعية -

$$
\text { جامعة بورسعيد }
$$

$$
\text { د / هبه الله أحمد البواب }
$$

مدرس قسم التربية الفنية - كلية التربية النوعية - جامعة بورسعيد

$$
\text { r. IN }
$$

$$
\text { مجلة التربية النوعية - العدد الثامن - يونيو } 1 \text { ـ ب r }
$$




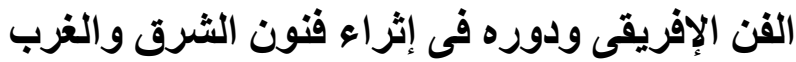

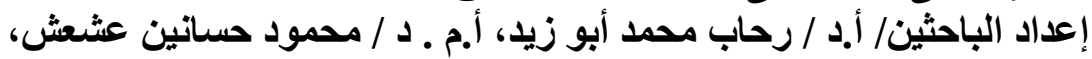

دـ / هبه الله أحمد البواب، أر دينا عصام محمد شييه

الفن الإفريقى ودوره فى إثراء فنون الشرق والغرب

اعداد

دينا عصام محمد شيبه

الدارسة بمرحلة الماجستير بقسم التربية الفنية - كلية التربية النوعية - جامعة بورسعيد

$$
\text { أ. أد/ رحاب محمد أبو زيد التربة الفية التربية }
$$

أستاذ الاثغغال الفنية قسم التربية الفنية - كلية التربية النوعية - جامعة بورسعيد

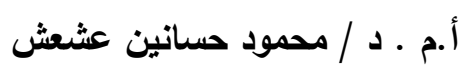

أستاذ الاثغال الفنية المساعد المتفرغ قسم التربية الفنية - كلية التربية النوعية - جامعة بورسعيد

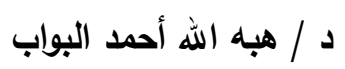

مدرس قسم التربية الفنية - كلية التربية النوعية - جامعة بورسعيد

ملخص البحث:

الفن الإفريقى كان له تأثير كبير على فنون العصر الحديث والمعاصر، ويسعى البحث

الحالى إلى إكتثاف صياغات تثكيلية قائمة على التوليف بين التقنيات والأساليب الفنية الحديثة للوصول إلى أعمال فنية متنوعة ومبتكرة مستعينا بالفن الإفريقى، الكثف عنف عن الاتجاه

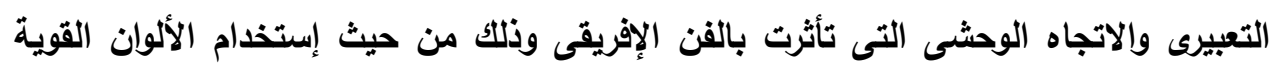

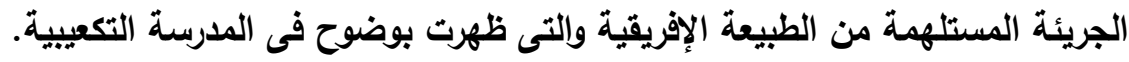

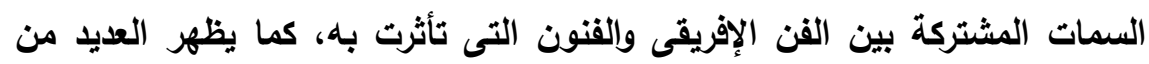

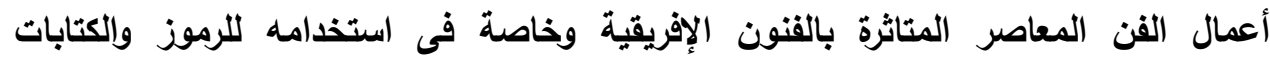

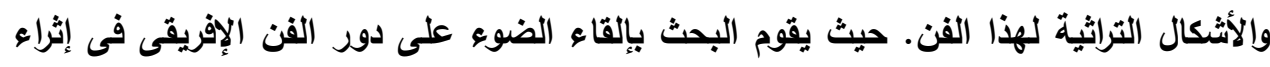

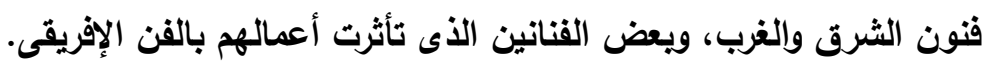

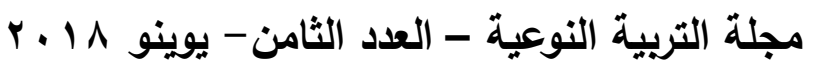




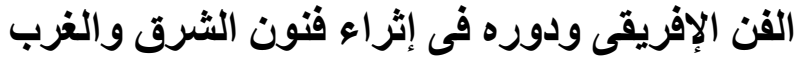

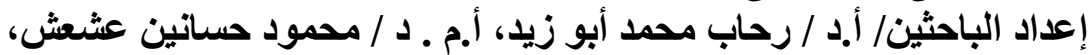

$$
\begin{aligned}
& \text { د / هبه الله أحمد البواب، أ/ دينا عصام محمد شيبيه }
\end{aligned}
$$

African art and its role in enriching the arts of East and West

By

Dina Essam Mohamed Shiba

- Master of Art Education - Faculty of Specific Education - Port Said University

Prof. Rehab Mohammed Abu Zeid

Professor of Art Works Department of Art Education - Faculty of Specific

Education - Port Said University

Dr. Mahmoud Hassanein Ashash

Assistant Professor of Technical Works Department of Art Education Faculty of Specific Education - Port Said University

Dr. Heba Allah Ahmed Al-Boab

Instructor of the Department of Art Education - Faculty of Specific

Education - Port Said University

\begin{abstract}
African art has had a great influence on modern and contemporary art, and the current research seeks to discover formulations based on the synthesis of modern technical techniques and techniques to reach a variety of artistic works using African art, the expression of the expression and the brutal trend affected by African art in terms of The use of strong bold colors inspired by African nature and which has emerged clearly in cubism school. The common features of African art and the arts affected by it, as well as many works of contemporary art influenced by African arts, especially in the use of symbols and writings and forms of heritage of this art. Where the research sheds light on the role of African art in enriching the arts of East and West, and some artists whose works were influenced by African art.
\end{abstract}

$$
\begin{aligned}
& \text { مجلة التربية النوعية - العدد الثامن - يوينو } 1 \text { ب r r } \\
& \text { <17\% }
\end{aligned}
$$




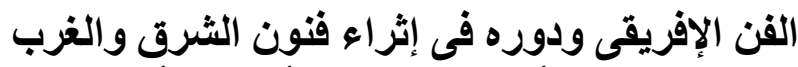

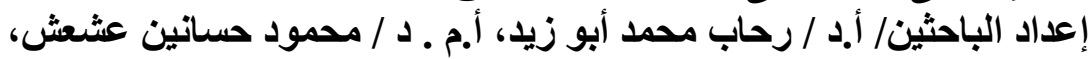

دـ / هبه الله أحمد البواب، أر دينا عصام محمد شييه

\section{خلقية البحث :}

يعد التراث واحداً من أهم المصادر الأساسية التي يعتمد عليها التدريس في معظم

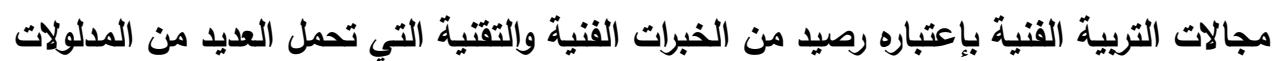
الثقافية والمنطلقات الفكرية التي ترتبط بحقبة زمنية بعينها ومن هنا كانت أهمية تناول التراث

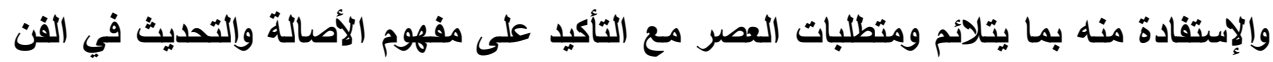
وعلى هذا فإن التوجه لدراسة التراث ينبغي أن يتم في ضوء البعاث البعد الجمالي المرتبط بلفسفته

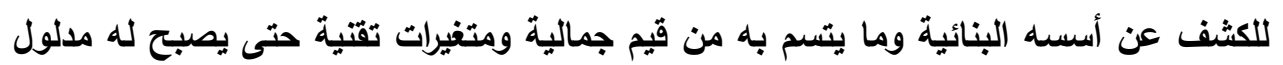

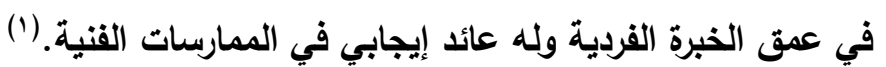
والجدير بالذكر"أ ن إتخاذ الفن كمدخل يتعلق بطريق الإستفادة منه، هل هل ينقل وتتم محاكاته التهاته

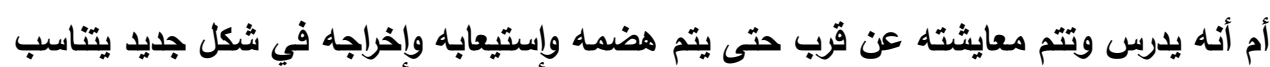

$$
\text { مع العصر الذي نعيش فيه" (؟). }
$$

حيث أن إنتزاع الفن من جذوره التي نمى فيها أو دراسته بدون علم بأهداف ومعتقدات

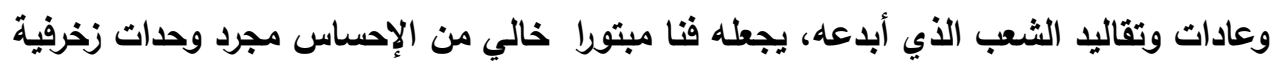

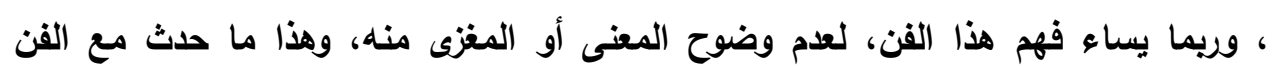

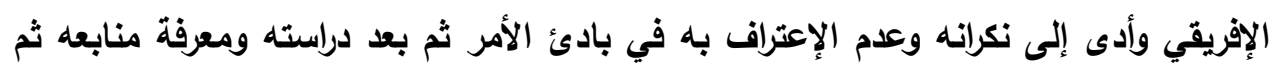

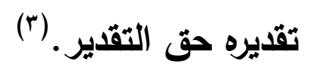

ويعتبر الفن الإفريقي من الفنون القائمة على إستلهام الفنان من الطبيعة وإلتراث

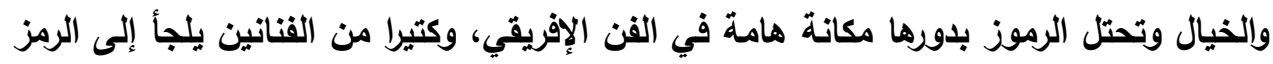

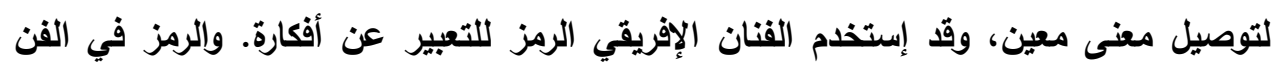

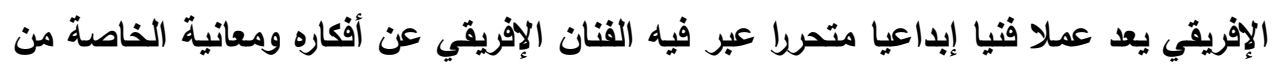

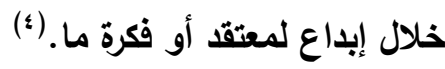

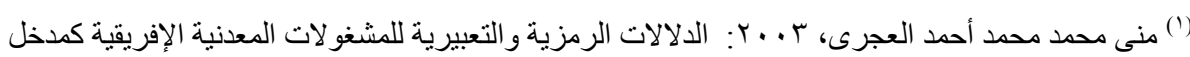

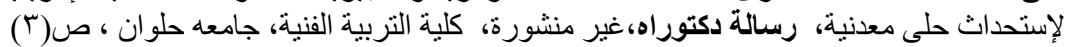

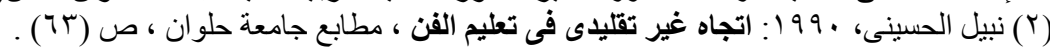

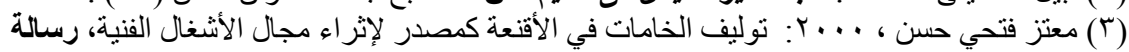

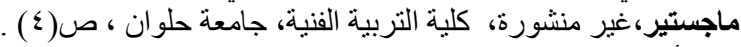

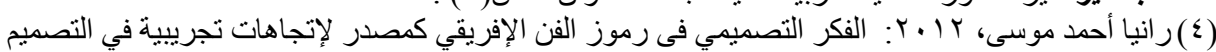

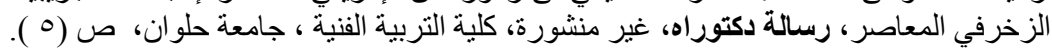

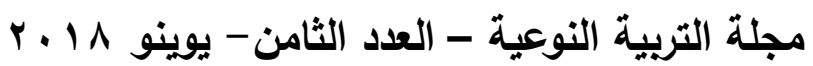
<19 


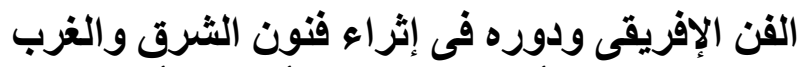

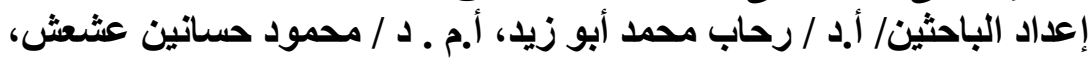

د / هبه الله أحمد البواب، أ / دينا عصام محمد شيبيه

مشكلة البحث:

• ما مدى تأثير الأبعاد التعبيرية والتراثية والقيم الجمالية والفنية للفن الإفريقى على

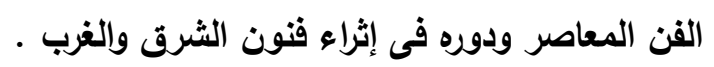

أهداف البحث:

• الإستفادة من خصائص ومميزات الفن الإفريقى وما يحتويه من جرأة لونية وتعبير

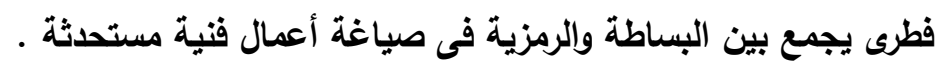

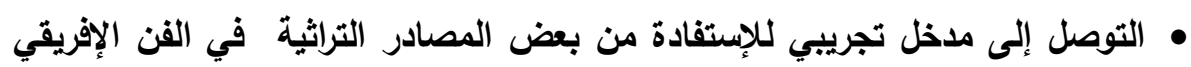
لعمل صياغات مستحثثة تكثف عن تعددية التشكيل لأعمال فنية معاصرة.

$$
\text { فروض البحث: }
$$

• أنه يمكن استحداث أعمال فنية معاصرة قائمة على مفهوم الأساليب والصياغات

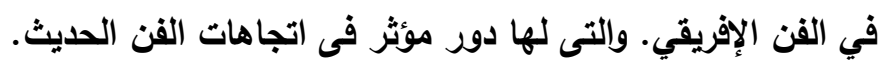
أهمبة البحث: في

توظيف القيم الجمالية التثكيلية التى تميز بها الفن الإفريقى فى صياغة أعمال فنية معاصرة.

توضيح مداخل الإستاهام فى الفن الإفريقى ومدى تأثيره على فنون الثرق والغرب.

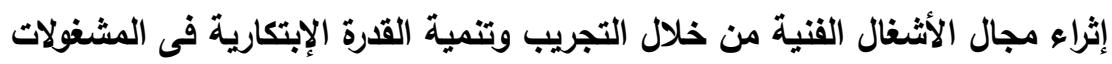
الفنية من خلال الفن الإفريقى كأحد الدداخل الهامة لتحقيق صياغات فنية مستحدثة.

$$
\text { يقتصر البحث على ما يلي: }
$$

• يهتم هذا البحث برصد الأعمال المعاصرة المتأثرة بالفن والتراث الإفريقى.

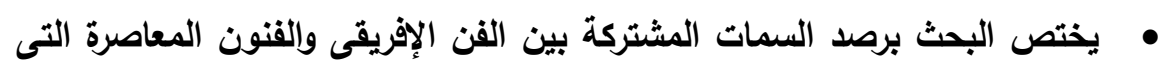

$$
\text { تأثرت به. }
$$

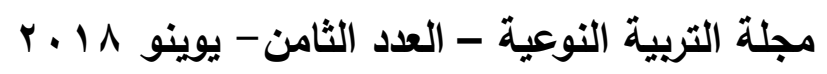




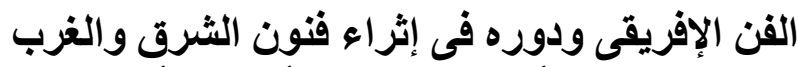

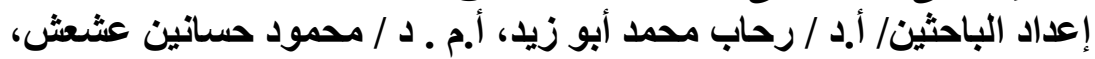

د / هبه الله أحمد البواب، أ / دينا عصام محمد شيبيه

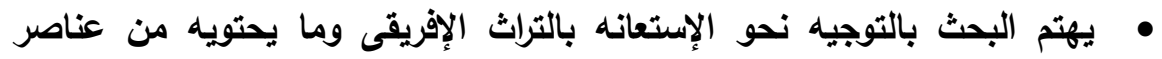
ورموز يمكن صياغتها فى اعمال فنية معاصرة.

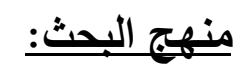

يعتمد البحث على المنهج الوصفى التحليلى وذلك من خلال:

عرض صور لتأثير الفن الإفريقى على فنون الثرق والغرب.

وصف وتحليل مختارات من الأعمال الفنية لبعض فنانى الحداثة وتأثرهم بالفن الأن

$$
\text { الإفريقى. }
$$

استخلاص بعض النقاط الفنية للعلاقة بين الفن الإفريقى والفنون المعاصرة التى

$$
\text { مصطلحات البحث: الفنرت الإفريقى: }
$$

" ظاهرة بشرية نبعت من أصل فردى جعلت منه محسوساً جمالياً ، لذا نجده يأخد طابعاً

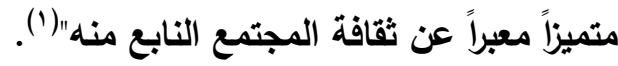

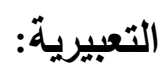

" الأسلوب الأى تقرره رغبة الفنان في ايجاد نظير تثكيلي لأحاسيسه المباشرة ولإستجاباته

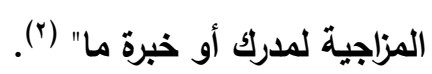

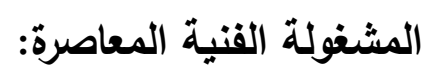

جاء فى المعجم الوجيز (عاصر) فلان فلاناً ، أى عاش معه فهى عصر واحد ، ومنها

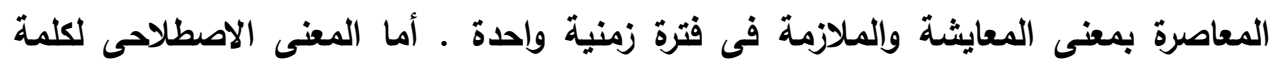

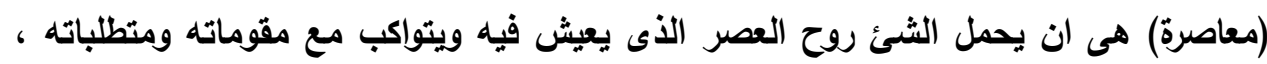

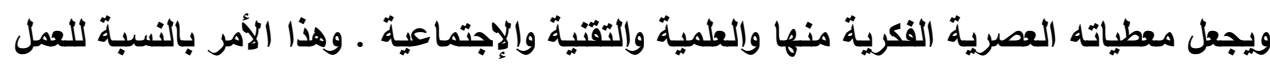

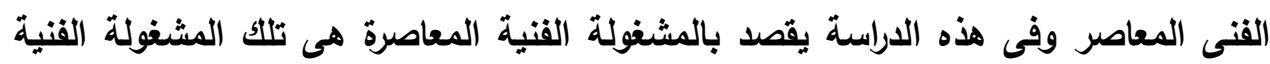

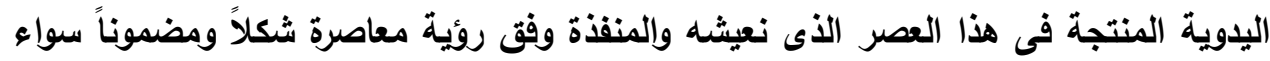

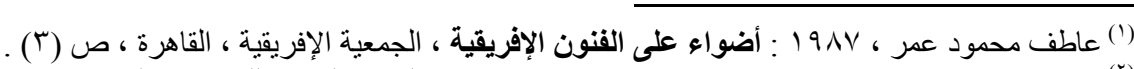

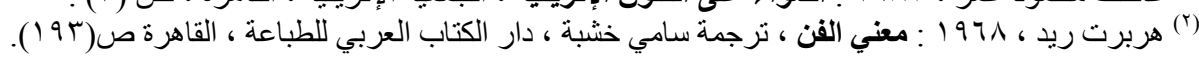

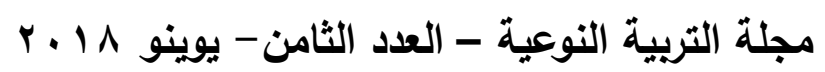




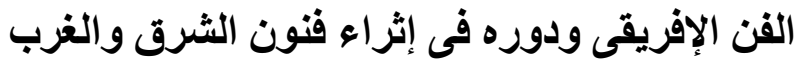

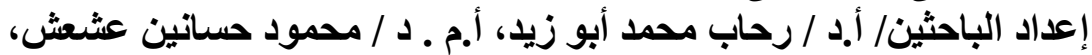

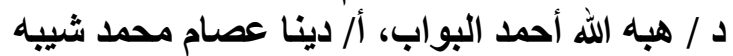

من حيث متغيرات التشكيل (الوظيفة، والتصميم، والخامات، والتقتيات) أو من حيث الأبعاد التعبيرية و المضامين المعنوية التى تنطوى عليهاب(1)

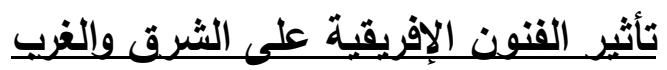

\section{الفن الافريقى كمصطلح}

يكاد يكون من الصعب البحث عن مسمى دقيق يصف فنون وسط وغرب القارة الافريقية

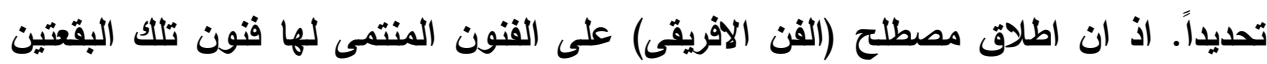
(وسط وغرب) افريقيا لا يعد بمثابة الوصف الدقيق لها على اعتبار ان الفن الافريقى مصطلح

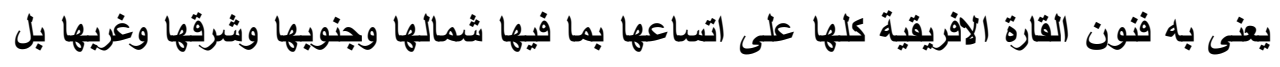
وقديمها وحديثها ، وايضا بما تثمله من فنون عرقية ودينية منميزة كالفنون المصرية القديمة

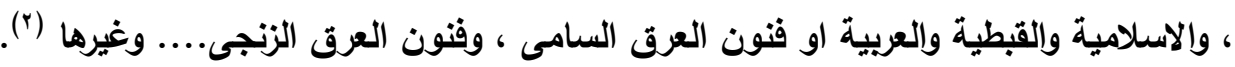

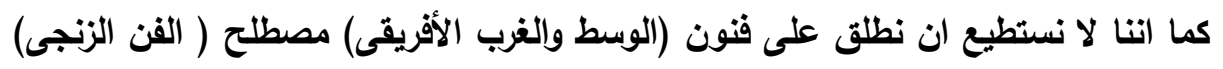

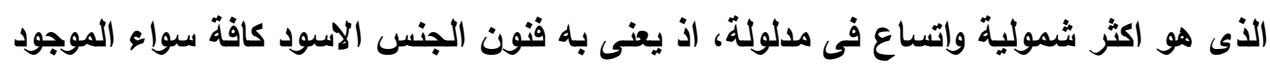

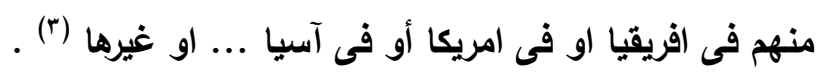

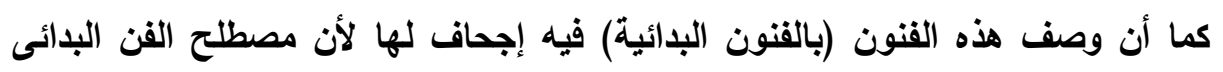

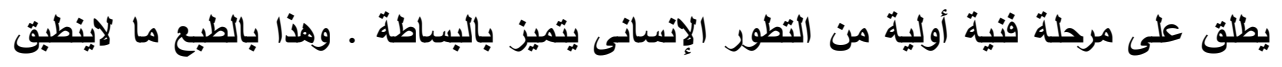

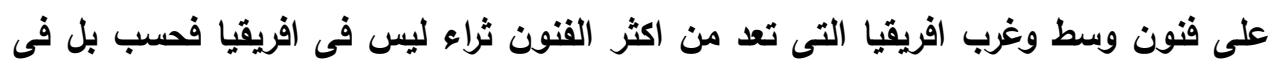

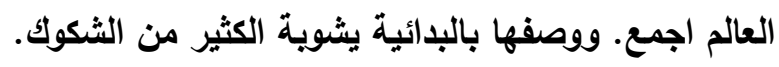

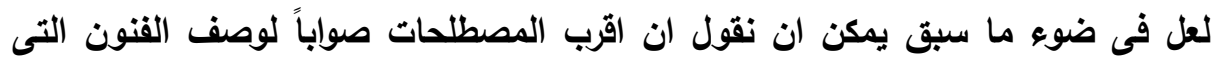
تنتمى لها منطقى وسط غرب افريقيا هو مصطلح ( الفن الافريقى الزنجى ) لما لهذا لهول المصطلح

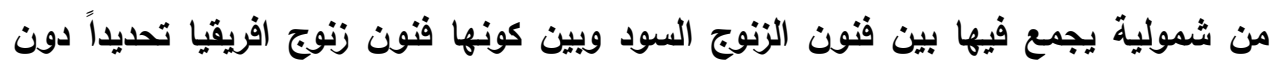

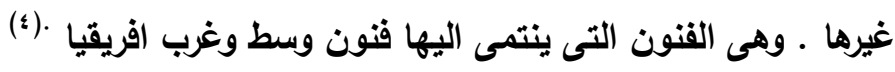

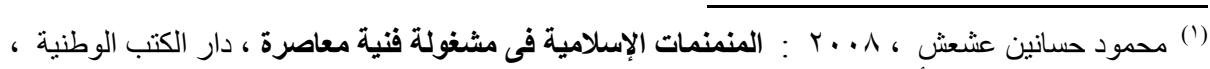

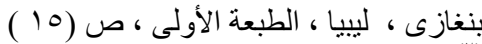

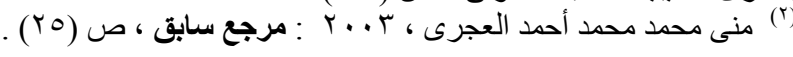

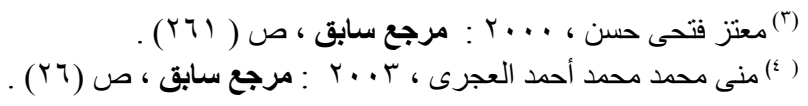

مجلة التريية النوعية - العدد الثامن - يوينو 1 ب r r S-1vi 
السمات المشتركة بين الفن الأفريقي والفنون المعاصرة التي تأثرت به :

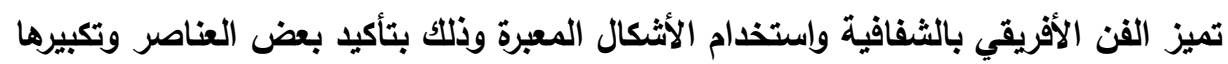

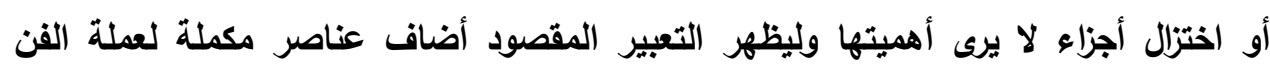

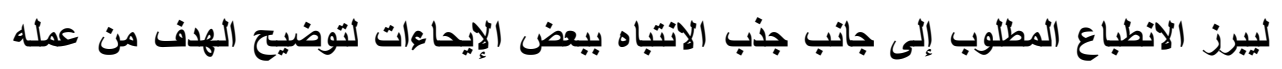

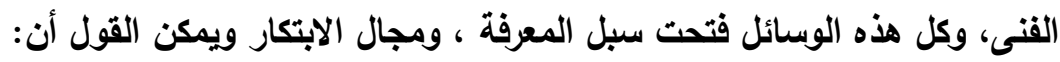

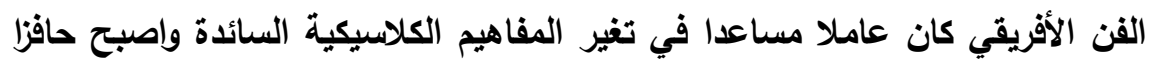

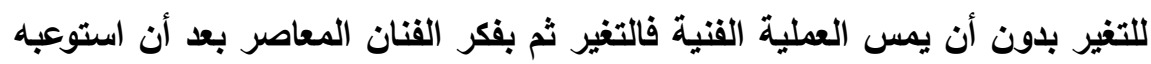

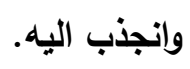

> أتجه الفنان الحديث إلى الفن الأفريقي فوجده نابعا من داخل الإنسان لإثباع حاجات

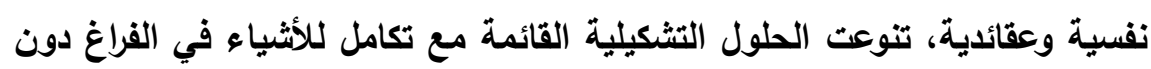
اللجوء إلى المنظور وتناول الفنان المعاصر تلك الحلول بمفهومة وثثقافته .

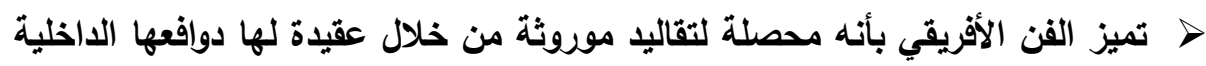
والتى انعكست في رموز دقيقة التفاصيل ، ويدل هذا على أن الأفريقي أوجد العلاقة

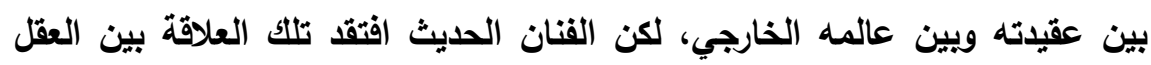

والمنطق والمعرفة. (1) > الفنان الأفريقى كان يختزل ويضيف للوصول إلى جوهر الأثياء سواء أكان هذاء

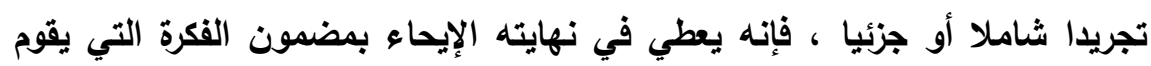

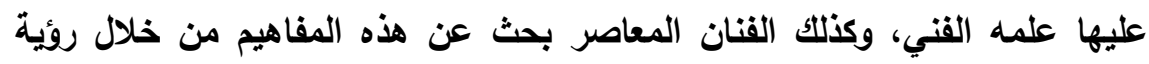
فنية متأنية تجمع بين ذاتية الفنان والتجريب في أن واحد. هكذا فان الوعى بما تثمله فنون الحضارات المختلفة وتعدد مصادر المعرفة، والروئية

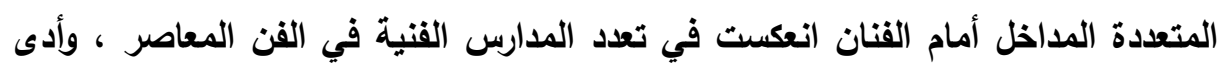

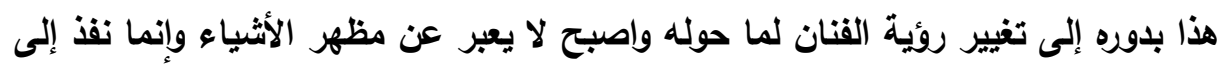

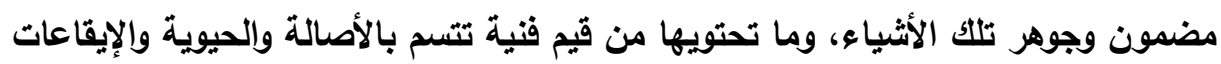

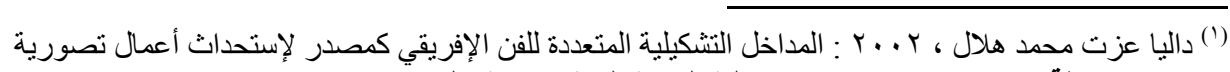

$$
\begin{aligned}
& \text { معاصرة، رسالة ماجستير ، غير منشورة، كلية التربية الفنية، جامعة حلوان .، ص (10 (1) ) . }
\end{aligned}
$$

مجلة التربية النوعية - العدد الثامن - يوينو 1 ب ـ 
المتناسقة والمتكاملة مع القيم التعبيرية والتشكيلية وكما قال "هربرت ريد" أن القواعد لا

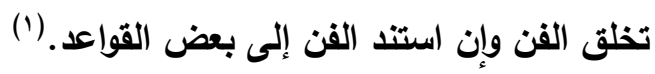

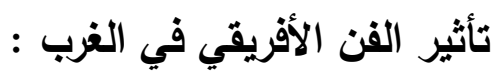

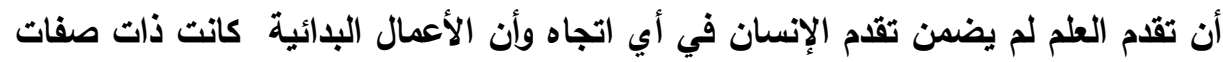

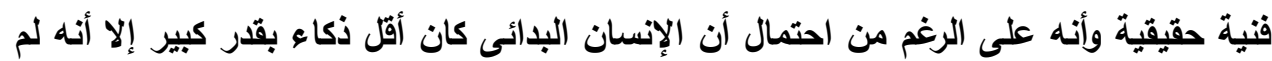

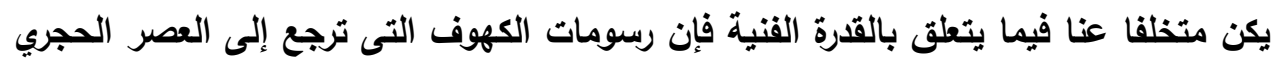

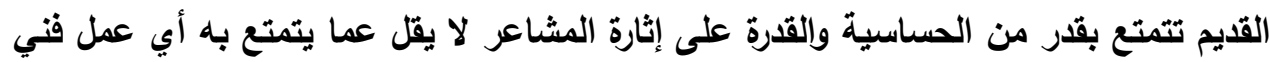

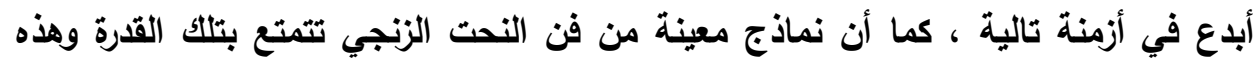

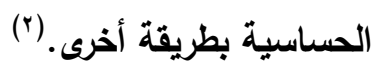

وأخذ الفن البدائي يثير اهتمام الفنانين الذين أبدوا حتى القرن التاسع عشر اهتماما سطحيا

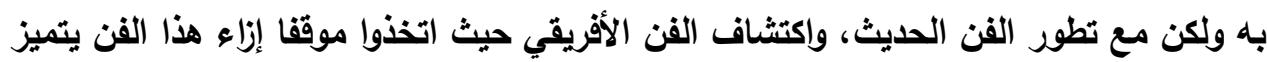
بالثحنة الانفعالية، أن الفنانين قلدوا عن وعي الفن البدائي وابرزوا حرية الروئية غير المقيدة

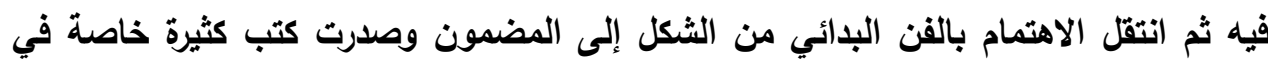

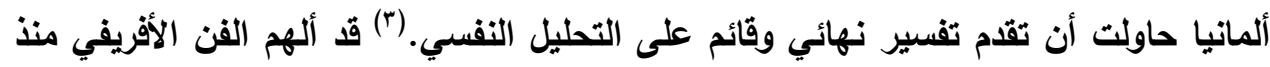

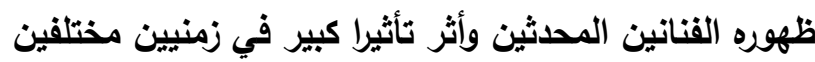

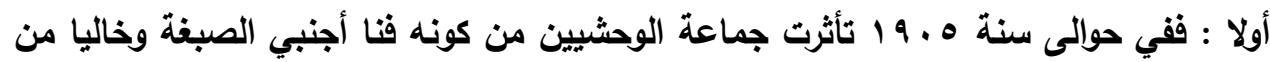

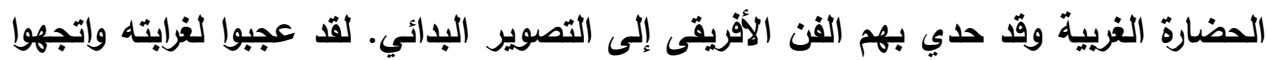

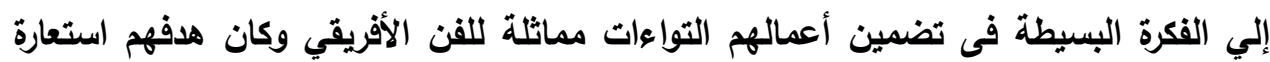

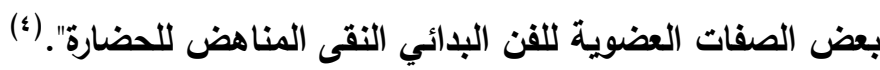

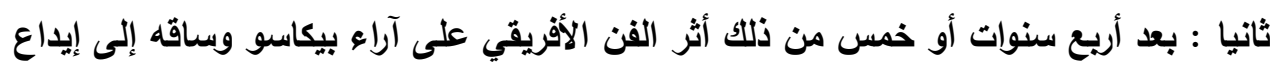
القن التكعيبي وكان التاثير أساسيا.

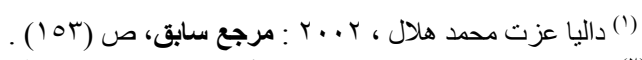

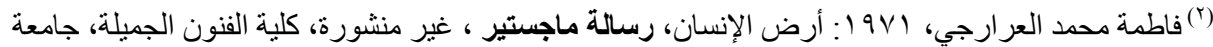


أن النحت الزتجي استطاع أن يثير القوة عن طريق استخدامه أثكالا هندسية مبسطة

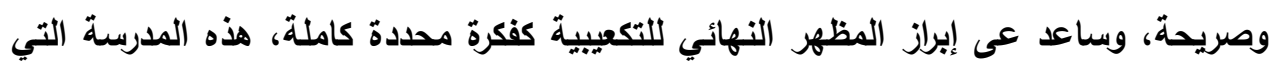
رأت أن جوهر الفن إنما يكون في قيمته الثكلية، وفيما يكون بين الخطوط والمساحات والأحجام

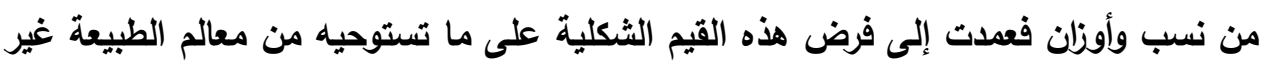
غائبة عن المعاني الوجدانية أو الثاعرية. بعد أن حاول التكييبيون تحويل هذه الهندسة

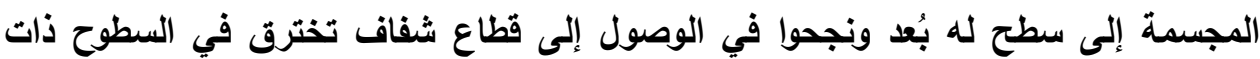

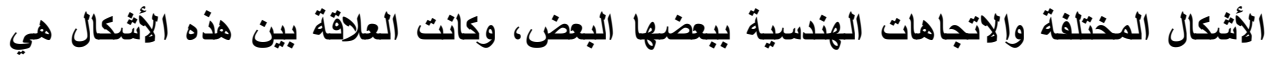
الفكرة الرئيسية في الموضوع على ذلك كانت النتيجة النهائية تتجه نحو البعد عن تمييز العنصر الذي استبدل بهيكل هندسة قائم فوق فراغ فضي، هذه الفكرة توجه الاهتمام إلى نظرية جمالية

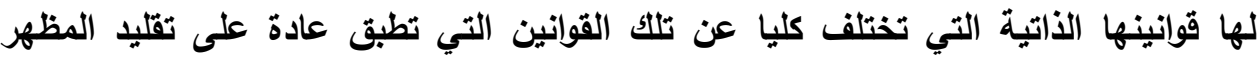
(1) الخارجي. (1)

ولقد أعجبت المدرسة التكعيبة بالفن الأفريقي لابتعاده الواضح عن محاكاة الطبيعة ولما يتصف به من قيم تثكيلية جادة غير أن هذا الفن هو تعبير عن مفهوم خاص للوجود

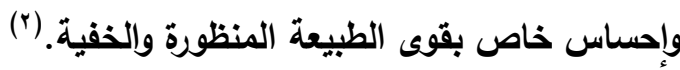
بعض الفنانين الأين تأثروا بالفن الأفريقي :

: Pablo Picasso بابلو بيكاسو

ويعتبر الفنان العالمي"Pablo Picasso" من أبرز فناني العصر الحديث الذين تأثروا بالأقتعة الإفريقية في أعمالهم فأنتج أبدع وأهم أعماله خلال مرحلته المسماه المرحلة الزنجية،

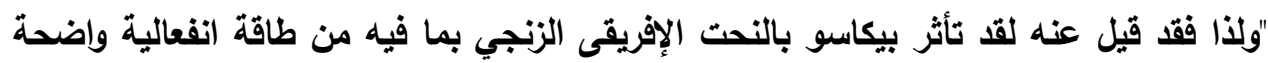
وقوة تعبيرية تجاه المجهول بأسلوب خشن ويساطة مجردة ملخصة لأهم مميزات الثئ، بجرأه وتعبيرية وتلقائية فطرية فنراه ينتج في لوحته الثهيرة (Les Demoiselles d'Avignon) ذات

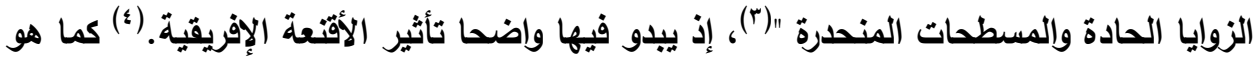

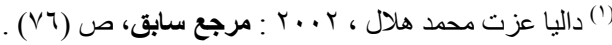

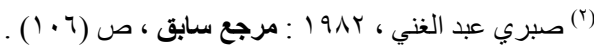

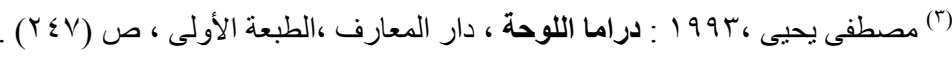

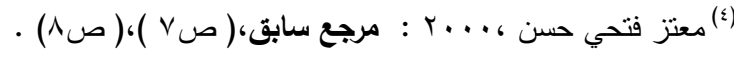

مجلة التربية النوعية - العدد الثامن - يوينو 1 | م r 


$$
\text { الفن الإفريقى ودوره فى إثراء فنون الثرق والغرب إباء }
$$

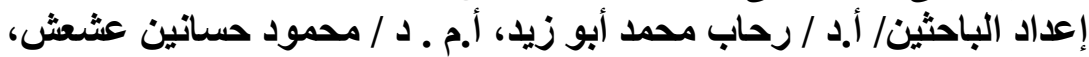

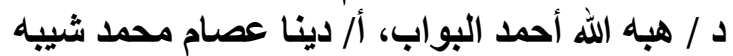

موضح بالثكل رقم (1)، وأيضا لوحته "Head of a Sleeping Woman " شكل رقم (ץ).

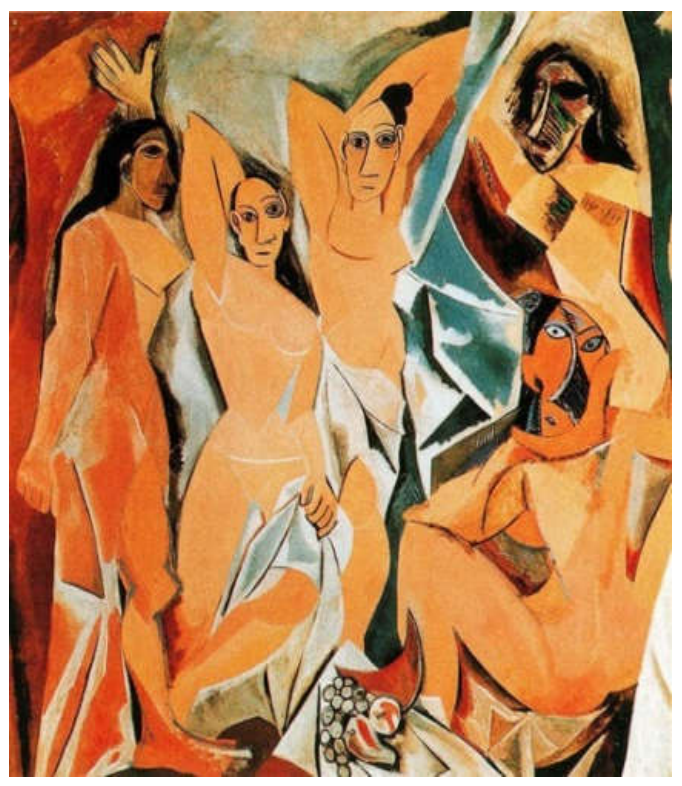

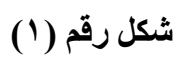

Pablo Picasso : اسم الفنان

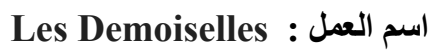

$$
\text { d'Avignon }
$$

الخامات : النفط ، قماش ، ألوان

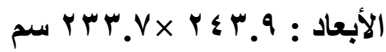

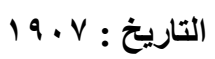

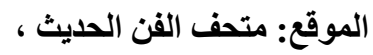

مدينة نيويورث، الولايات المتحدة التهن

$$
\text { المصدر: }
$$

www.theartstory.org

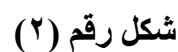

Pablo Picasso : : اسم القنان :

Head of a Sleeping : اسم العمل : Woman الخامات : زيت على قماش

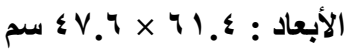

$$
\text { التاريخ : }
$$

الموقع : متحف الفن الحديث ، نيويورك المصدر: https://en.wikipedia.org

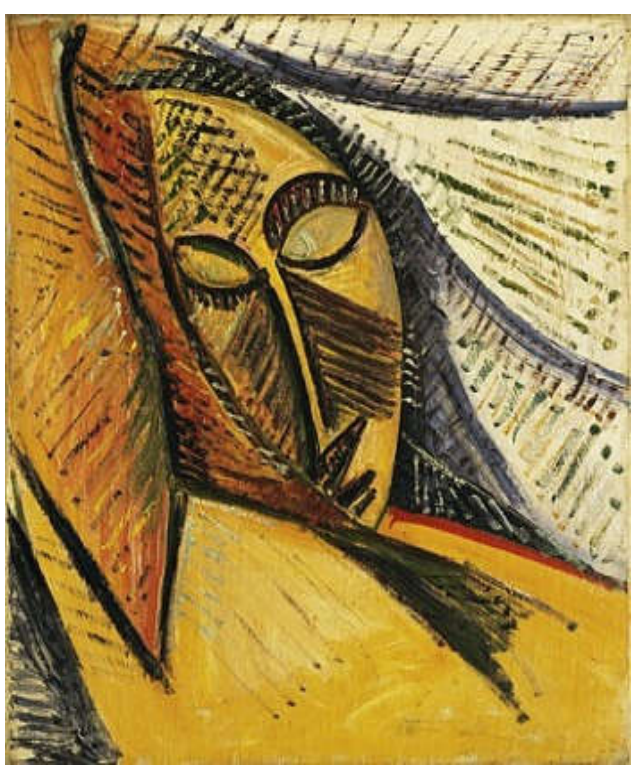

مجلة التريية النوعية - العدد الثامن - يوينو 1 ب r r

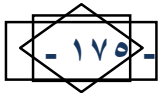




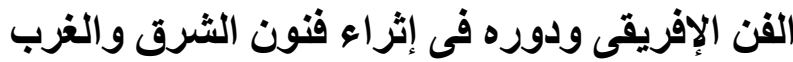

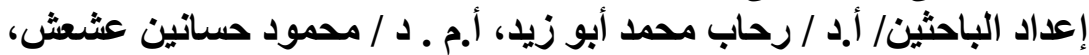

د / هبه الله أحمد البواب، أ/ دينا عصام محمد شيبه

" فتيات افينون Les Demoiselles d'Avignon "كانت تلك اللوحة نتيجة لشهور طويلة

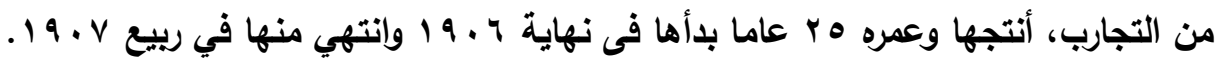

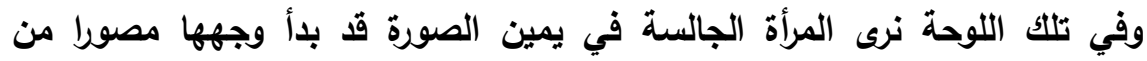
الجانب ثم صور وضع آخر والتفت الوجه أكثر إلى الرائي وكان من نتيجة تلك اللفتة ظهور جزئ من الصدر حتى تتناسب اللفتة مع منطق الإمكانيات البدنية التشريحية وفي الصورة النهائية

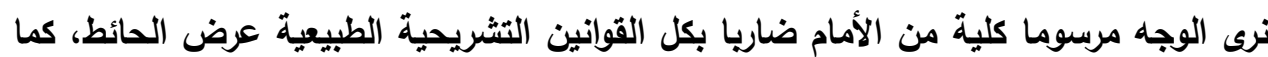

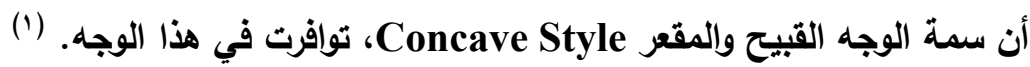
هذا الحل التشكيلي النهائي هو سمة أفريقية تماما، حيث أن الفنان الأفريقى عند فأند

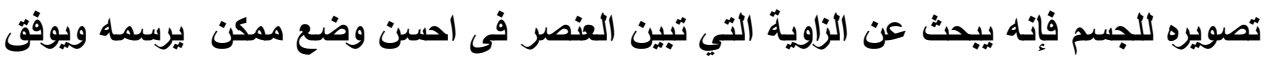

Maillol بين الزوايا المختلفة المختارة ليؤلف منها جسما يعبر به عما يريد، ويقول مايول ائل

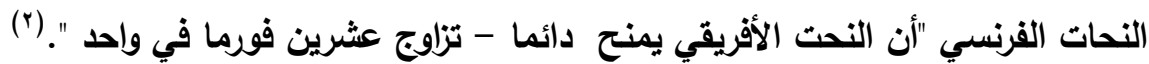

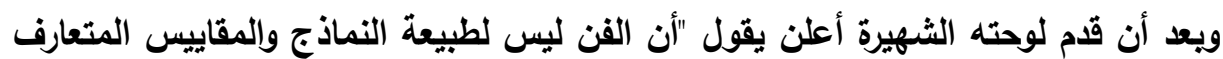

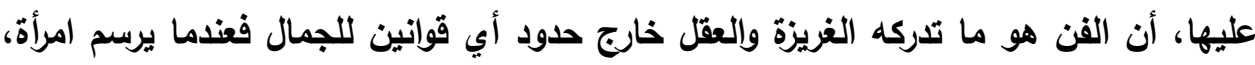

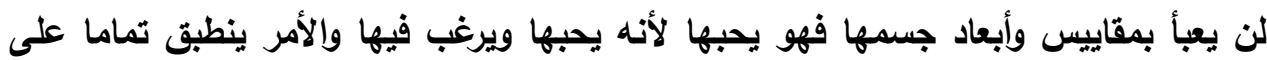

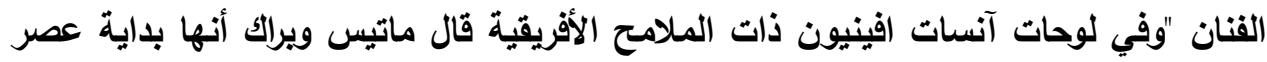

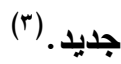

: Constantine Brancus كونستنتين برانكوزي قدم برانكوزى حلولا في تكوين الرؤوس ذات الثكل البيضاوي المائل وترى معالجته ذات

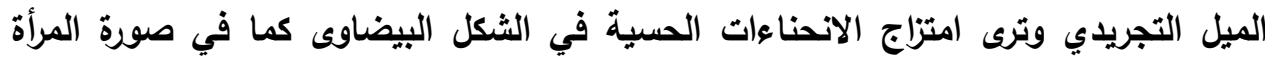
الآنسة بوجاني شكل رقم (r)، والمكونة من مجوعة من الأقواس والمنحنيات. وفي القطعة الفئل المسماة الزنجية البيضاء الموجودة بمتحف فيلادفيا للقنون شكل رقم(؛)، ويظهر الثكل البيضاوي للرأس وشكل الثفاه التي توحي بالتأثر بالوجه الأفريقي ويبدو بساطة التعبير ونعومة لفئة

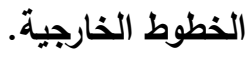

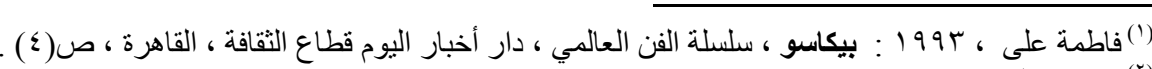

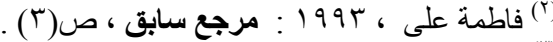

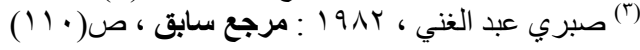

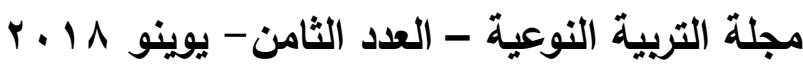
Sivis. 
الفن الإفريقى ودوره فى إثراء فنون الثرق والغرب إباء

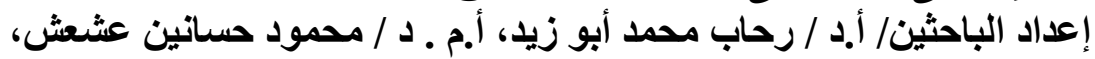

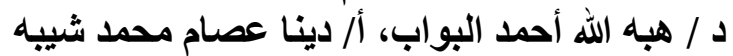

كذلك استوحى من الرموز الأفريقية القطعة المسماة الملك، و يظهر عصر الغموض والوقار

والقوة كما أن كل أعماله تتسم بقوة كامنة غير محدودة. (')

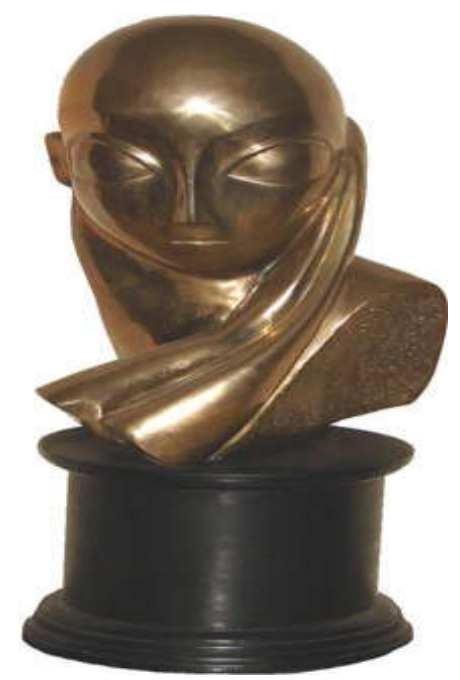

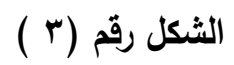
أسم العمل : Madamoiselle
Pogany
المرأة الآنسة بوجاني - ماني

أسم الفنان:Constantine Brancus

النمط: التعبيرية

التصنيف: النحتئة

https://www.wikiart.org : المصدر
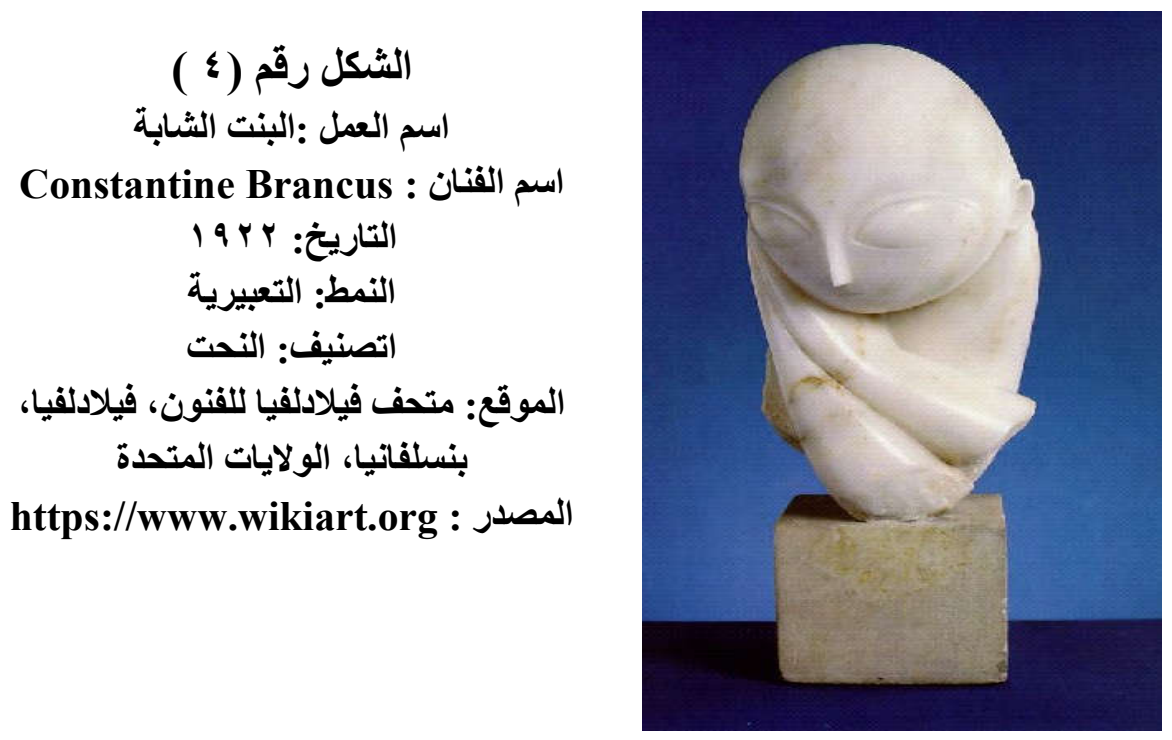

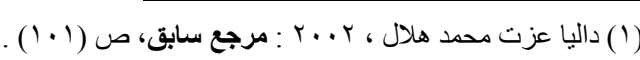

مجلة التربية النوعية - العدد الثامن - يوينو 1 ب r r 


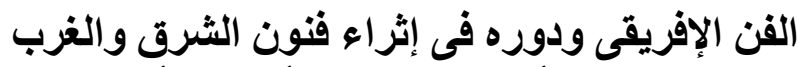

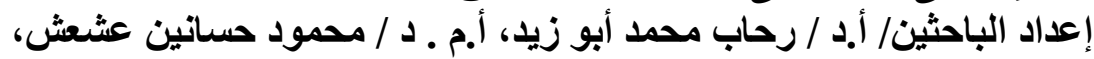

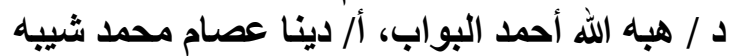

: Amido Modliani أميدو مودلياني مصور ومثال من أسرة ايطالية يهودية، بأ يلقن الفن فى فلورنسا والبندقية الى أن استقر

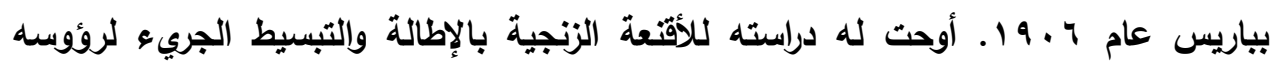

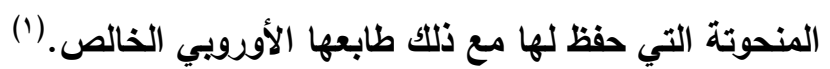

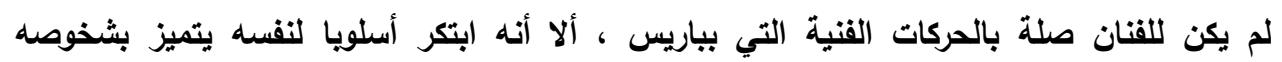

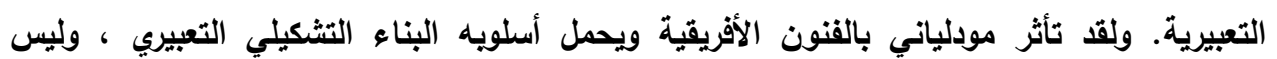

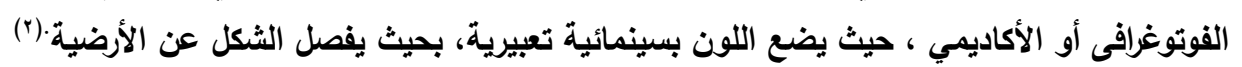

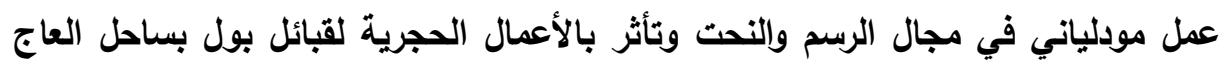

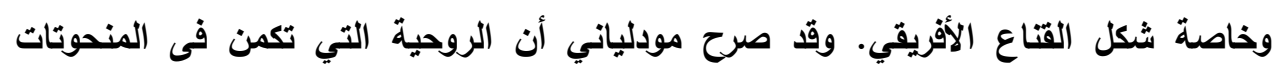
الأفريقية تحرك النفس نحو التجريد المعبر وتبسيط الثكل في صراحة ووضوح واختصار الفئل المعالم

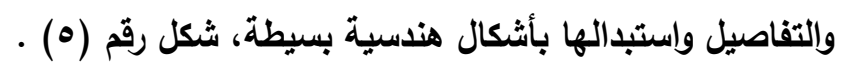

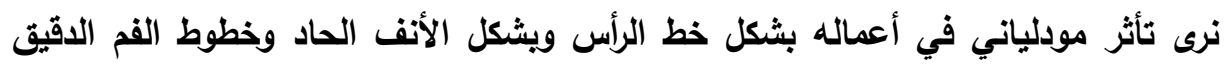

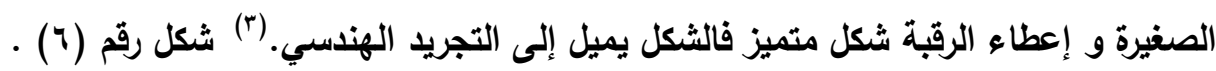

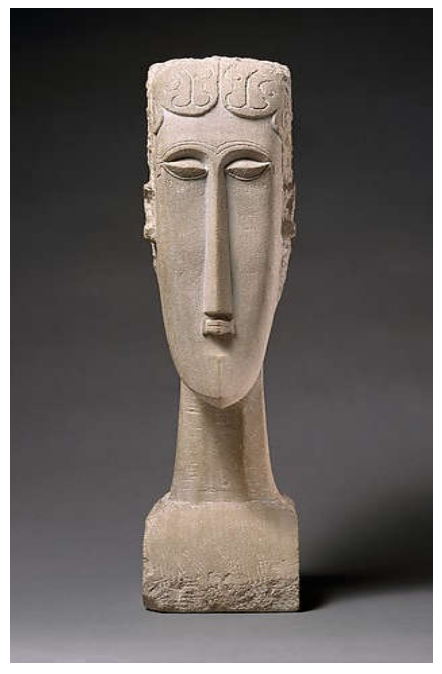

$$
\begin{aligned}
& \text { شكل رقم (0) }
\end{aligned}
$$

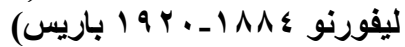

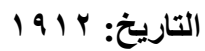

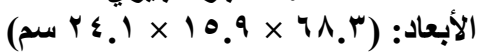

$$
\begin{aligned}
& \text { الوزن: ه v رطل ( ع ب كجم) } \\
& \text { التصنيف: النحت } \\
& \text { المصدر : النصت }
\end{aligned}
$$

https://www.metmuseum.org/art/col lection/search/

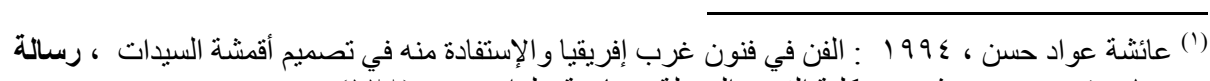

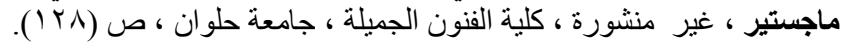

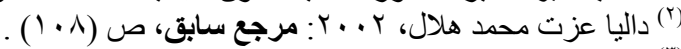

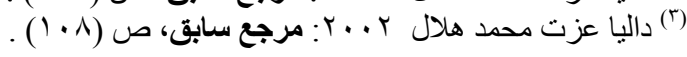

مجلة التربية النوعية - العدد الثامن - يوينو 1 | ب r 
الفن الإفريقى ودوره فى إثراء فنون الثرق والغرب إباء

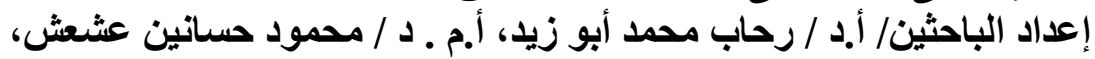

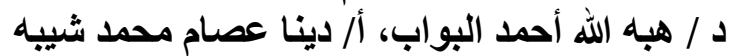

$$
\begin{aligned}
& \text { شكل رقم (" ) } \\
& \text { باريس) } \\
& \text { المصدر : }
\end{aligned}
$$

https://www.metmuseum.org /art/collection/search/

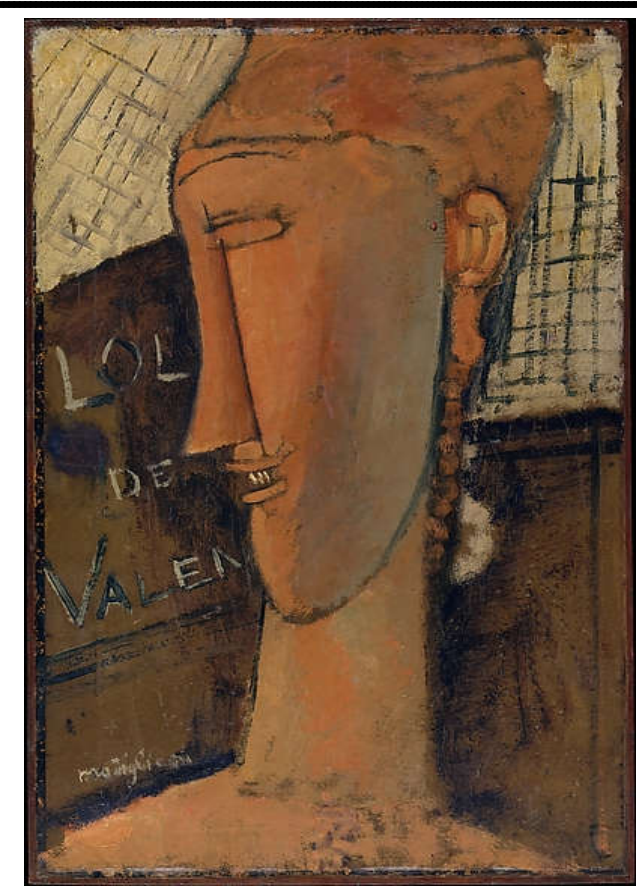

تأثر الفنان المصري بالفن الافريقي :

(الفنان حامد ندا (ع 9 ( 9 - - 99 ( ) )

ولد حامد ندا في نوفمبر سنة ؛ ج 9 و وحصل على دبلوم القنون الجميلة بالقاهرة عام

1901 وسافر في بعثة لأسبانيا حيث حصل على دبلوم التصوير من أكاديمية الفنون الجميلة

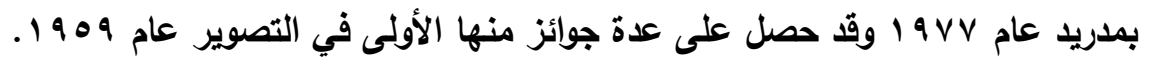

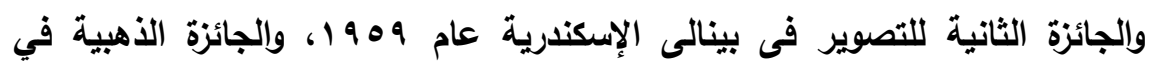

بينالي الكويت عام ه V 19، وقد أنتجت كعنصر شرف بالمركز الثقافي لحوض البحر الأبيض في

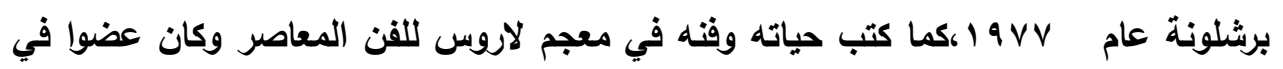
هيئة التدريس بكلية الفنون الجميلة جامعة حلوان ثم رئيسا في شعبة التصوير الجدارى في

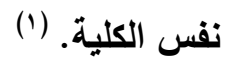

(1) صبرى محمد عبد الغنى ، 1990 : بدايات الحركة التثكيلية ومسار الجماعة الفنية فى مصر ، القاهرة ، ص

مجلة التريبة النوعية - العدد الثامن - يوينو 1 ا .

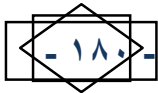




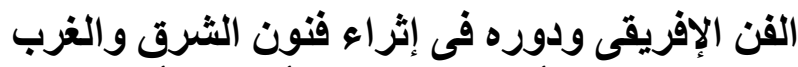

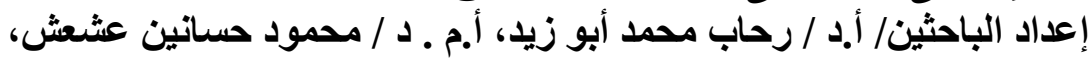
د / هبه الله أحمد البواب، أر دينا عصدام محمد شيبه

لقد استطاع الفنان حامد ندا مند الأريبينيات أن يهضم مختلف الاتجاهات القنية وأن

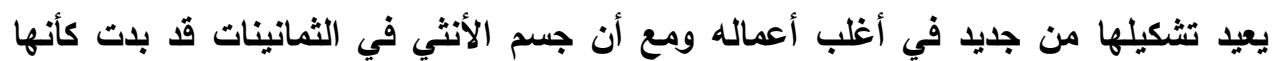

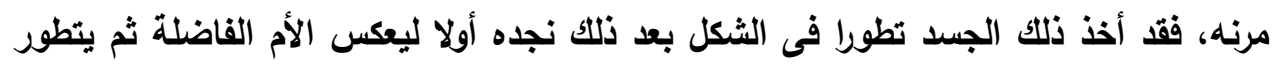
ليكون رمزا للإخصاب ثم يبدو بعد ذلك عنصر جنس - وأخيرا ليصبح شكل يتعلق ويرتبط بفكرة

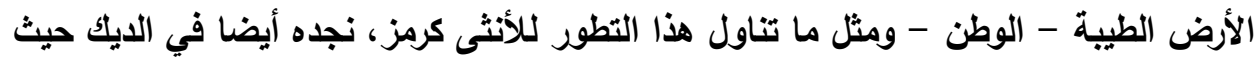

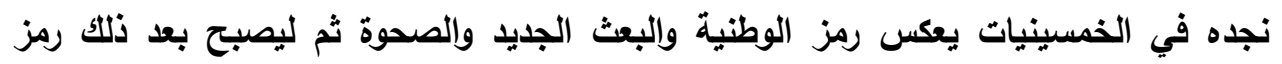

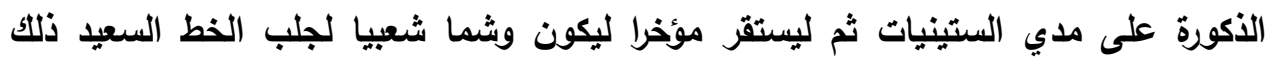
يصدق في باقي العناصر مثل السكة، الطيور والزواحف حيث نجد الرمز قد مر في عدة مراحل

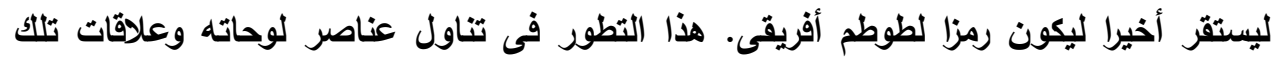

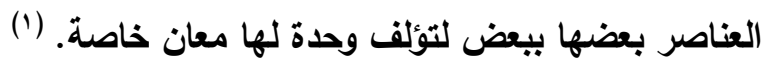

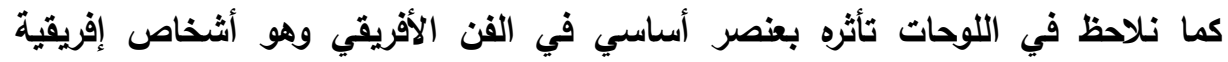
محرفة، كما نجد حوار الأثخاص مع الطير يماثل حوار التماثيل مع الحيوانات والطيور.

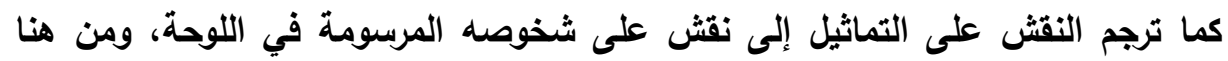

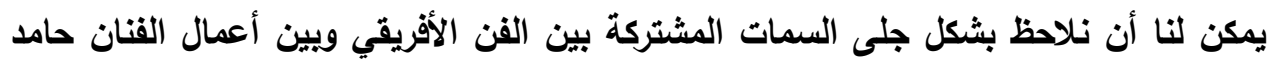

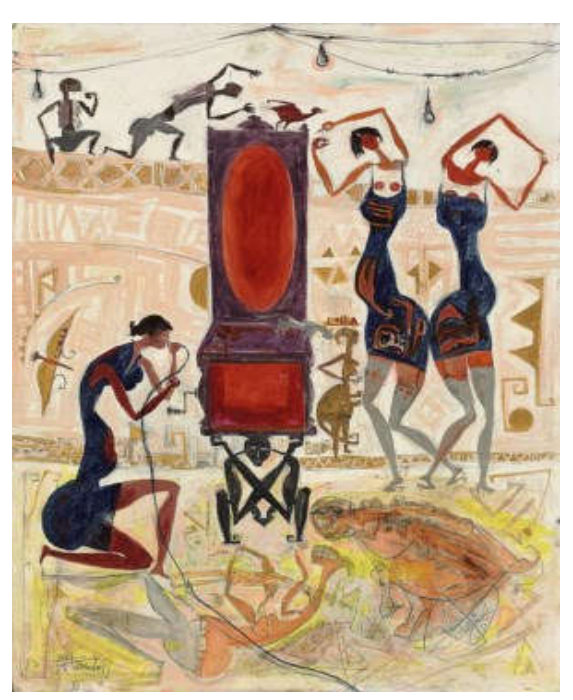

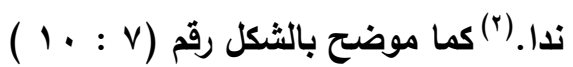

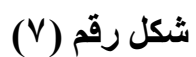
القنان : حامد ندا اسم العمل : المغني والبيانو

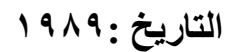
الخامة : النفط وقلم رصاص على لوحة قماش

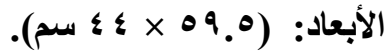
المصدر : www.christies.com 
الفن الإفريقى ودوره فى إثراء فنون الثرق والغرب إباء

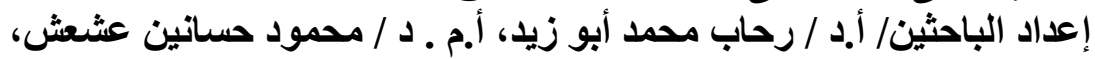

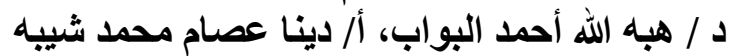

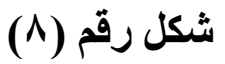

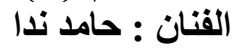

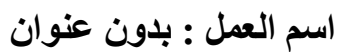

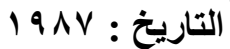 \\ الخامة : زيت على قماش : الاش

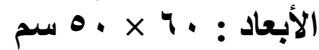 \\ المصدر : الم \\ http://www.artnet.de
}
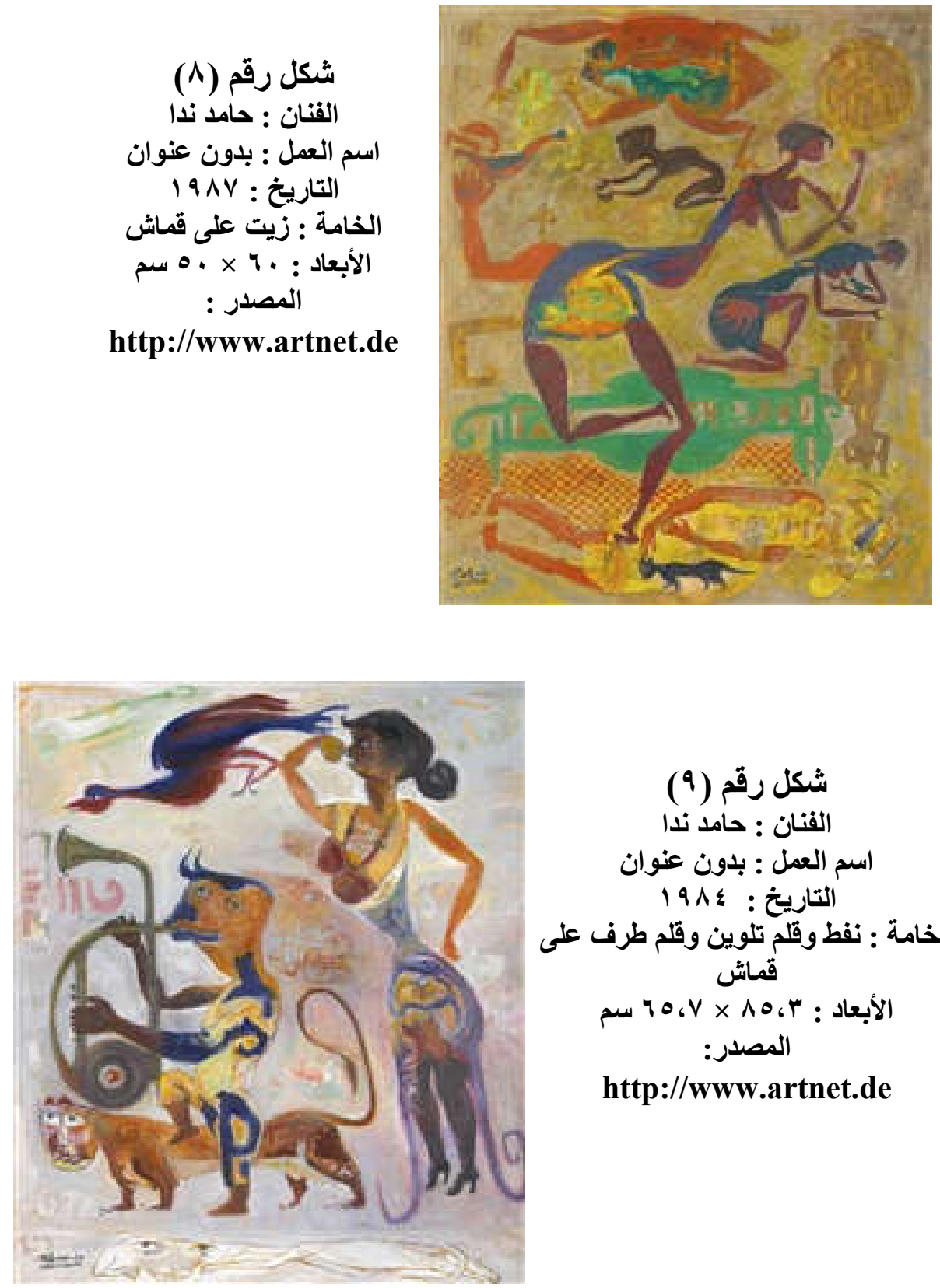

$$
\begin{aligned}
& \text { شكل رقم (9) } \\
& \text { الفنان : حامد ندا } \\
& \text { اسم العمل : بدون عنوان : الفوان }
\end{aligned}
$$

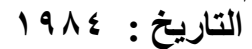

$$
\begin{aligned}
& \text { الخامة : نفط وقلم تلوين وقلم طرف على } \\
& \text { قماش }
\end{aligned}
$$

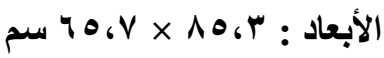

$$
\begin{aligned}
& \text { المصدر: }
\end{aligned}
$$

مجلة التربية النوعية - العدد الثامن - يوينو 1 ب ب r 
الفن الإفريقى ودوره فى إثراء فنون الثرق والغرب إباب

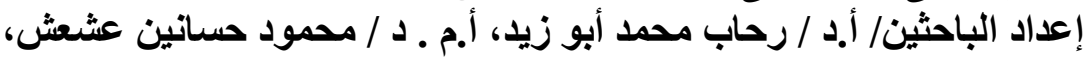

د / هبه الله أحمد البواب، أ/ دينا عصام محمد شيبه

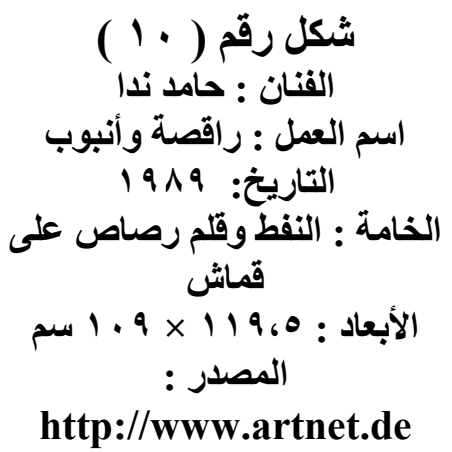

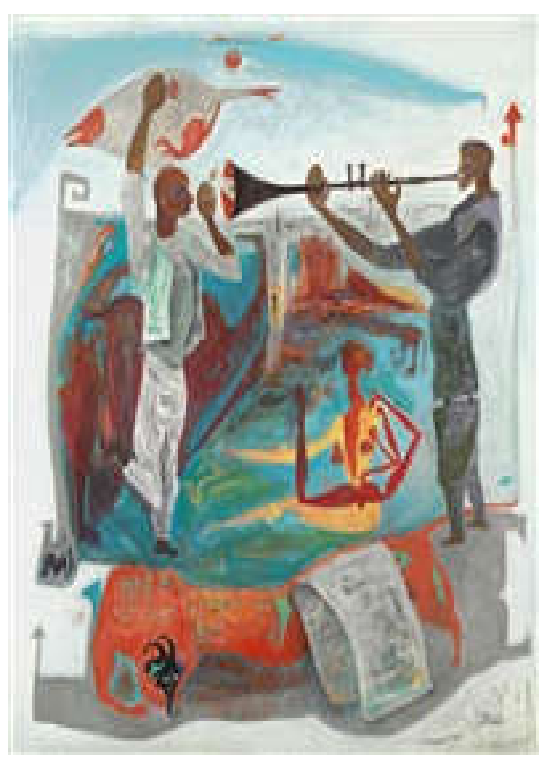

مجلة التريية النوعية - العدد الثامن - يوينو 1 ب . 


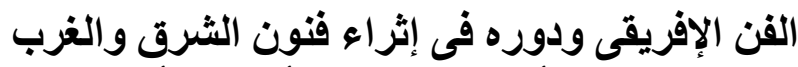

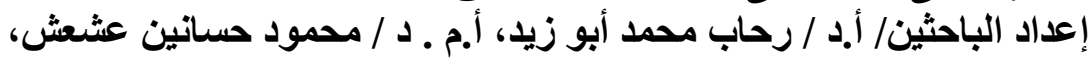

د / هبه الله أحمد البواب، أر دينا عصدام محمد شيبه

نتائتج البحث :

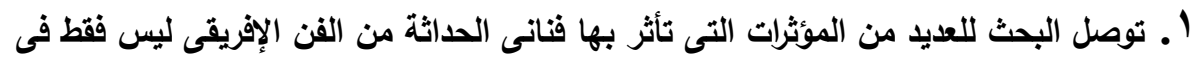

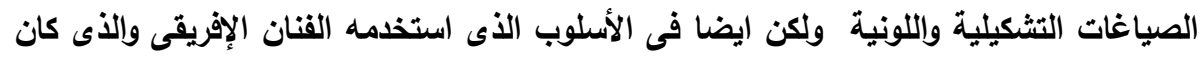
يجمع ما بين البساطة فى صياغة عناصرة وبين صياغته الوحشية الحرة فى تعبيره اللونى .

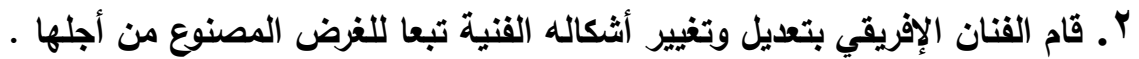

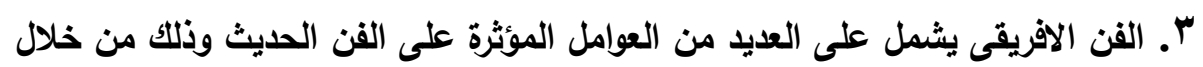

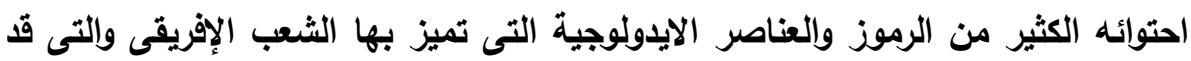

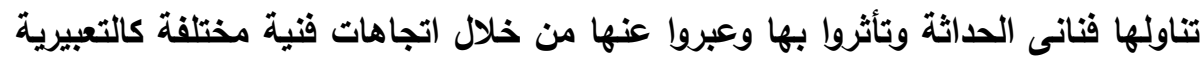

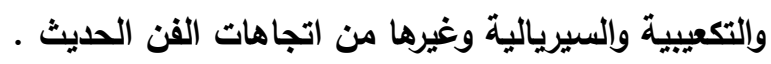

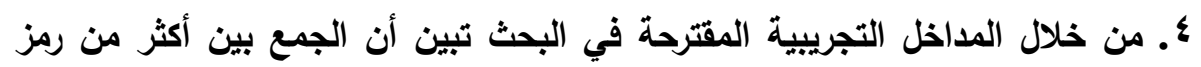

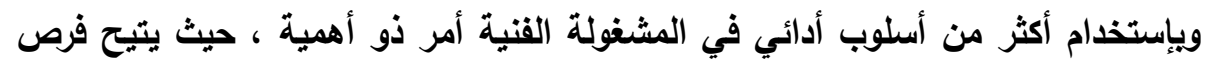
أوسع للتجريب والممارسة وحرية التعبير والتشكيل .

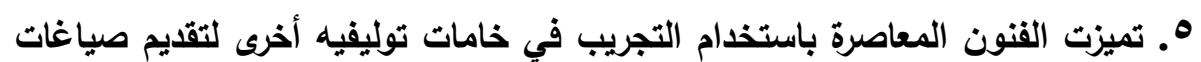
جديدة مستحدثة في مجال الفنون . \. تعتبردراسة الفن الإفريقي من المصادر الهامة في مجال الفن والأثغال الفنية لتنوعه ومرونته التصميمية. V. نجح الفنان الإفريقي رغم قيود معتقداته الدينية في استخدام الفن الافريقى في وتئي

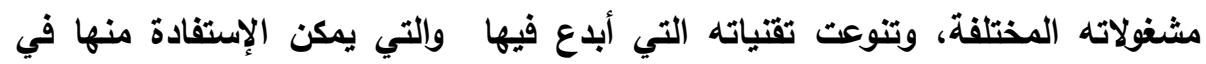
استحداث مشغولات فنية مبتكرة.

توصبات البحث: تطرح الباحثة بعض التوصيات وذلك في ضوء ما توصلت إليه من نتائج في هذا البحث وهذه التوصيات تتحدد في الآتي: التئه بوض التوصيات 1. ادراج الفن الافريقى كإحد المداخل الفنية في المقررات الدراسية لتدريس مادة الأثغال الفنية بشكل عام بكليات التربية الفنية والفنون ككل.

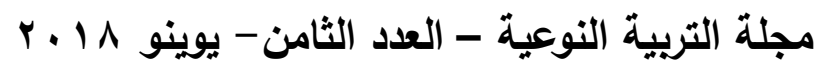
<-1ns- 


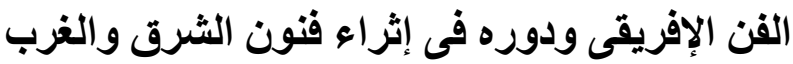

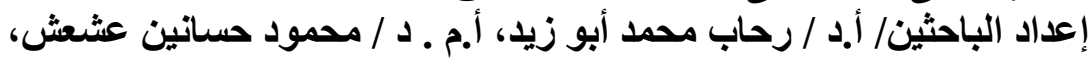

د / هبه الله أحمد البواب، أر دينا عصام محمد شييه

r. اجراء المزيد من البحوث والدراسات عن الفن الإفريقي وتحليله ومعرفة مدلولاته، وذلك

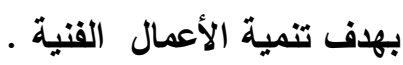

r. يفتح البحث أمام الباحثين الآخرين في مجالات الفنون المختلفة بصفه عامه والفن

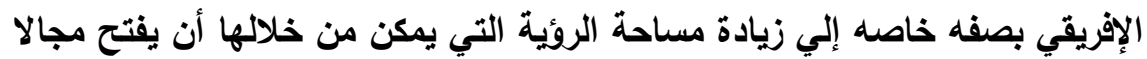

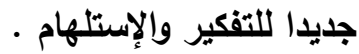
؛. ضرورة الإستفادة من فنون الحداثة في مجال الأثغال الفنية لإنتاج حلول وصياغات

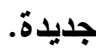

•. زيادة الإهتمام بالفنون الإفريقية، ودراسة إمكانية تحويرها وتجريدها لتناسب الأعمال القنية الحديثة ومواكبة التطور العصري. T. اتاحة الفرصة للفنانين الأفارقة لإقامة معارض خاصة لإصة بالتراث الإفريقي بصفه دورية،

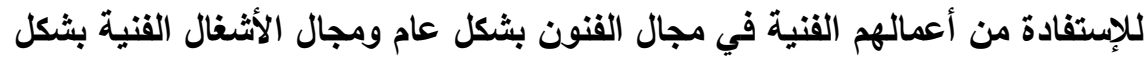

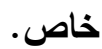




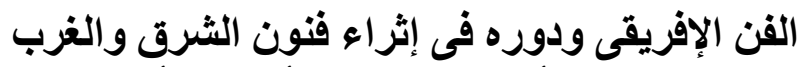

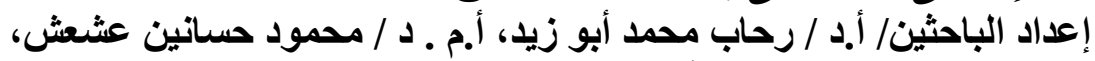
د / هبه الله أحمد البواب، أل أد دينا عصام محمد شيبيه

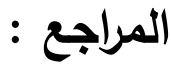

أولا :الكتب العربية :

صبرى محمد عبد الغنى ، 1990 : بدايات الحركة التثكيلية ومسار الجماعة الفنية فى مصر ، القاهرة.

(Y) عاطف محمود عمر ، 19AV : أضواء على الفنون الإفريقية ، الجمعية الإفريقية ، القاهرة.

فاطمة على ، برو 199 : بيكاسو ، سلسلة الفن العالمي ، دار أخبار اليوم قطاع الثقافة ،

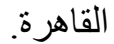

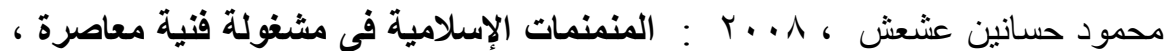

دار الكتب الوطنية ، بنغازى ، ليييا ، الطبعة الأولى.

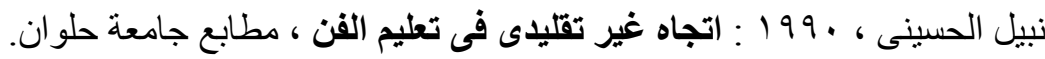

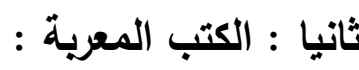

هربرت ريد، 1971 : معني الفن ، ترجمة سامي خثبة ، دار الكتاب العربي للطباعة ،

القاهرة

ثالثا : الرسائل العلمية : الثرة

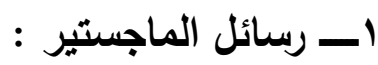

داليا عزت محمد هلا، ب ...r: المداخل التتكيلية المتعددة للفن الإقريقي كمصدر

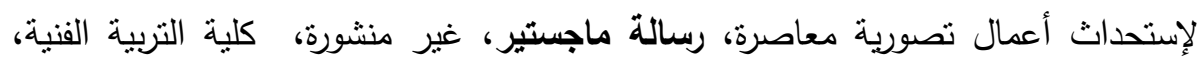

جامعة حلوان.

فاطمة محمد العرارجي، ا9V| | أرض الإنسان، رسالة ماجستير ، غير منشورة ، كلية

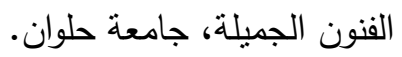

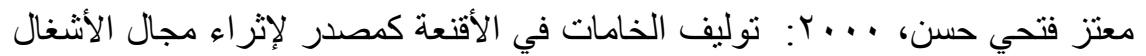

الفنية، رسالة ماجستير ،غير منشورة ، كلية التربية الفنية ، جامعة حلوان.

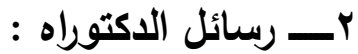

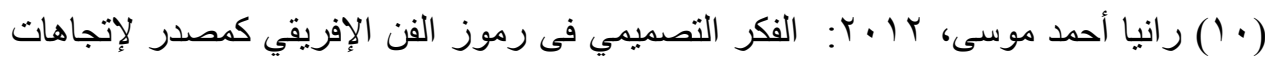
تجريية في التصميم الزخرفي المعاصر، رسالة دكتوراه،غير منشورة، كلية التربية الفنية، جامعة

مجلة التربية النوعية - العدد الثامن - يوينو 1 ب ـ r 


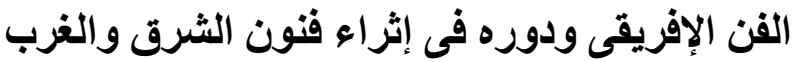

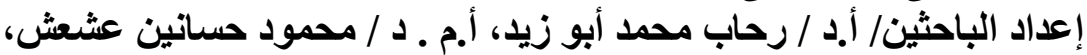

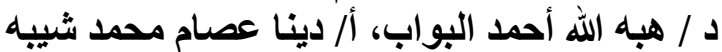

(1) صبري عبد الغني، r 1911: السمات الإفريقية في تصوير بيكاسو ، رسالة دكتوراه ، غير

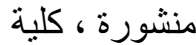

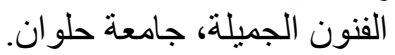

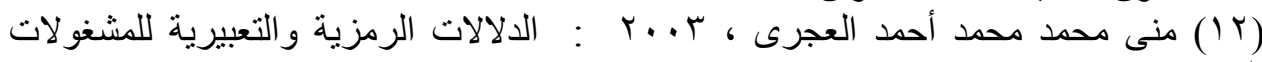
المعدنية الإفريقية

كمذل لإستحداث حلى معدنية، رسالة دكتوراه ،غير منشورة ، كليه التربية الفنية ، جامعه

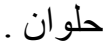

(13) http://www.artnet.de

(14) www.christies.com

(15) https://www.metmuseum.org

(16) https://www.wikiart.org

(17) www.theartstory.org

(18) www.visual-arts-cork.com

(19) https://en.wikipedia.org

خامسا : المواقع الإكترونية :

مجلة التربية النوعية - العدد الثامن - يوينو 1 1 ب r

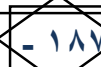

